\title{
2006-1621: WHY SHOULD I CARE? STUDENT MOTIVATION IN AN INTRODUCTORY PROGRAMMING COURSE
}

\section{Helen Burn, University of Michigan}

Helen Burn is a doctoral candidate at the Center for the Study of Higher and Postsecondary Education at the University of Michigan. She holds a master's degree in mathematics and focuses her work on undergraduate mathematics and science learning and teaching.

\section{James Holloway, University of Michigan}

James Paul Holloway is Professor of Nuclear Engineering \& Radiological Sciences at the University of Michigan. His technical research is in the area of computational kinetic theory, especially neutron and gamma ray transport theory in nuclear reactor analysis and in inverse problems related to neutron and gamma radiation, and in nonlinear dynamics and control. He has served as course coordinator for the College of Engineering's first year course, Engr 101, Introduction to Computers and Programming, since its creation in 1997. 


\title{
Why Should I Care? Student Motivation in an Introductory Programming Course
}

\begin{abstract}
This study builds on research conducted by the College of Engineering at the University of Michigan in collaboration with the School of Education, the Minority Engineering Program Office, and industrial supporters, which exposed problems with student motivation in a required, first-year course in computing and programming. This paper describes the nature of an instructional intervention designed by the lead instructor for the course aimed to increase students' perception that computer programming and algorithmic thinking are (1) important and (2) useful to engineering majors. The conceptual framework for the study derives from Wigfield and Eccles ${ }^{10}$ expectancy/value model of student motivation. Multiple regression analysis of student survey responses revealed that students in the treatment group were more likely than those in a comparable, untreated, group to believe it is important that engineering majors learn to program, which suggests that instructors can directly influence student motivation. The treatment group was no more likely than the comparison group to believe that the ideas from the course would be useful in their future careers. This finding is partly attributable to our inability to control for the nature of the weekly assignments in the untreated group, which confounded our ability to fully evaluate the effect of the intervention on students' perception of the usefulness of the course. Gender, race/ethnicity, and prior programming experience were not significant predictors of perceptions of importance or usefulness. Student interest in the weekly programming assignments was the biggest predictor of agreeing that the course was important and useful, followed by a student's self-reported proficiency in programming. This result provides empirical evidence of the potential benefit of placing programming assignments in the context of technology applied to the improvement of society, to current events, or to technologies with which the students are familiar. An analysis of historical course grades - acknowledging the limitations of doing so - revealed that the gap between males and females and between minority and majority students narrowed during the semester of the intervention compared with a year earlier. Future interventions to bolster student motivation should include measures aimed specifically at improving programming proficiency, because our model predicts that lower levels of programming proficiency might cancel out the positive effect of creating interesting contexts for the weekly assignments as well as the positive benefits of directly addressing with students the importance of programming to engineering majors.
\end{abstract}

\section{Introduction}

The College of Engineering at the University of Michigan enrolls about 1200 new students each Fall and requires them to take several courses during their first year. Among the required courses is Engineering 101: Introduction to Computers and Programming [Engin 101]. The core objectives of Engin 101 are to develop students' open-ended thinking skills and to enhance problem-solving skills. These skills are developed as students create and write programs using $\mathrm{C}++$ and MATLAB. The course provides students with an opportunity to practice an engineering problem solving process by starting from an open problem statement, developing an understanding of the requirements of the problem and the physics or mathematics behind it, 
formulating a solution as an algorithm, and then implementing it, iteratively refining that solution, testing its adequacy as a solution to the original problem, and judging its aesthetics. With its focus on the algorithmic solution to problems, the course requires students to develop logical thinking and organizational skills. The course also provides students with an introduction to a tool-programming — that they will use in later classes and in their careers.

Engin 101 is organized into large lecture sections of 225 students. Students in each lecture section are then broken into lab/discussion sections of 25 students each. A faculty member oversees each lecture section and supervises 3 graduate student instructors who each lead 3 lab/discussion sections. There are generally 3 lecture sections each term, but these are often run largely independently of each other, other than a shared set of course objectives. The curriculum (syllabus, assignments, exams) is homogeneous within each lecture section and its coupled lab sections. While there is variation from lecture section to lecture section, course assignments generally include 8 to 12 projects whose solution requires the implementation of an algorithm in either $\mathrm{C}++$ or MATLAB, along with 6 to 8 hours of exams.

Faculty in the college of engineering worked carefully on the course design given the abundant evidence that first-year experiences play a key role in inspiring students to continue on in engineering ${ }^{7,8}$. Particularly challenging was the large-lecture format of Engin 101, which is an organizational constraint that is unlikely to change. Using the ABET criteria as a framework, faculty developed clearly stated course objectives (http://www-

eng101.engin.umich.edu/Objectives/) linked to Bloom's taxonomy ${ }^{1}$. Most faculty teaching the course try to select assignments that they hope will illustrate the application of computing to solve problems in mathematics and science. The goal is usually to connect the class with the calculus and physics classes. Informal group or teamwork is encouraged, but work is generally submitted individually, and the teaching assistants for the course are carefully selected by faculty. Students have access to multiple sources of feedback for their work, sometimes including an autotester that provides instant feedback on their computer code.

Despite the effort put into course organization and content, data collected by the College of Engineering suggested that the course presented a formidable challenge for some students and in particular might be discouraging women and underrepresented minorities from pursuing degrees in engineering. Specifically, between 1999 and 2002, 29 percent of under represented minority students (African American, Hispanic/Latino, and Native American students) received a grade of C- or below compared to only 12 percent of all Engin 101 students. Further, there was a reported .7 gap in average course GPA between underrepresented minorities and majority students (white and Asian/Asian-American), and a .4 gap between females and males.

In Fall of 2003, researchers from the School of Education triangulated survey data collected during the first and eighth week of the semester (64 percent response rate) with interviews of 20 students after the course concluded. Together, this data led to a working hypothesis that many students did not perceive computer programming and algorithmic thinking as important and useful to their future as engineers or even as engineering majors, and that this perception was having a negative effect on their motivation to engage in the course material. For example, there was a statistically significant mean decrease of $0.5(p<.01)$ between the initial and follow-up surveys to the question: "I can see/imagine how the ideas from this class will be applied in my 
future career" $(1=$ strongly agree....5 = strongly disagree $)$. Differences by gender were not significant. For under-represented minorities there was a drop of 1.38 in their agreement with this question, but this must be viewed in the context of the very small sample $(n=8)$ of underrepresented minority students responding to both the initial and follow-up surveys.

Further, 75 percent $(15 / 20)$ of the interview participants, including students who self-reported achieving high grades in Engin 101, did not consider programming and algorithmic thinking to be key features of their identities as engineers, and they did not understand how programming would be utilized in their chosen majors. Roughly half of the interview respondents did not think they would program in the future. Usefulness and importance are two dimensions of student motivation that have been shown to affect persistence and achievement ${ }^{6,10}$. In this case, the interviews revealed that, by virtue of the structure of the course, students developed strategies that would ensure that they received a passing grade, such as over relying on group work and the autotester. However, these strategies did not reinforce their learning of the concepts of the course sufficient to reach high standards on their exams. It was success on the latter that the research team believed contributed most to the grade disparity.

At this point, the lead instructor for the course made the decision to develop instructional interventions to deal directly with student perceptions rather than to enact measures such as limiting the amount of group work or the use of the autotester. The purpose of this paper is to describe the nature of the intervention and to present the results of follow-up study that measured the effects of the intervention.

\section{Literature Review}

Student apathy or lack of motivation in a required course might be an expression of students' resentment at being required to take the course or might be an indication of an absence of intrinsic motivation to learn. The work of Tobias ${ }^{9}$ suggests that failure to motivate students drives many students away from engineering. Faculty can motivate students toward course goals by increasing the value of learning and by increasing students' belief that engaging in course activities will aid them in achieving their educational or career goals ${ }^{4}$.

A well-researched model of student motivation used to inform this study is Wigfield and Eccles ${ }^{10}$ expectancy-value model. Expectancy refers to expectancy for success or how well students believe they will do on a task. This is also referred to in the literature as self-efficacy. Students' expectancy for success is a strong predictor of their performance. For example, if students perceive they are unlikely to be successful on an exam, they are less likely to study for the test $\mathrm{t}^{5}$. The value component of the expectancy-value model refers to task value and relates to whether a student cares about a task they are asked to engage in during a course. High levels of task value have been shown to be positively associated with higher levels of achievement ${ }^{5}$.

Value is broken down into four components: (1) attainment value or importance, (2) intrinsic value or interest, (3) utility value or usefulness, and (4) cost. Attainment value pertains to identity issues and the personal importance to the student of doing well on a task. Students view tasks as important when they view them as connected to their sense of self. For example, engineering students will believe a task is important if engaging in the task reflects on their identity as an 
engineering major. Gender and racial identity become salient when talking about attainment value because tasks offer opportunities to demonstrate aspects of one's self-conception, such as masculinity or femininity or connection with cultural heritage.

Intrinsic value pertains to the enjoyment a student gains from doing a task and relates to interest and intrinsic motivation. Interest has been shown to be course specific. And although students may not be interested in a course at a global level, an individual course or topic within a course can activate interest ${ }^{4}$. Utility value is connected to how a task fits into students' future plans. Students will be more motivated to engage in an assigned task if they believe it is relevant to their future academic or career goals. Students may perceive some course assignments as more useful than others and as a result be more or less engaged in the task. Research on gender and science suggests the important role that perceived societal usefulness plays in female's interest in science, with female students more frequently bringing contextual concerns to their studies, such as an interest in solving societal problems or in helping others ${ }^{2,3}$.

Finally, cost refers to the sacrifices the student makes in completing a task. For example, is it worth it to the student to study sufficiently to receive an A on an exam? Negative aspects of doing a task, such as fear of failure or success, are considered when conceptualizing of cost. Students develop coping strategies to avoid negative costs like failure by choosing easy tasks, over relying on groups, or procrastinating. Students who procrastinate in studying for an exam are able to attribute their lack of success to their procrastination rather than their aptitude; and if they are successful on the exam, they can attribute their success to superior aptitude.

For the Fall 2004 term, the lead instructor developed a two-pronged instructional intervention aimed to increase students' perception that computer programming and algorithmic thinking are important and useful to their future as engineers or engineering majors. The intervention was aimed at all students. While we felt confident the intervention would help students new to programming, we also believed it would positively influence students who already identified strongly with computer culture- a culture where coding is a reflection of personal value, selfworth, and identity but where it may not have high attainment value to students as engineering majors.

\section{Description of the Intervention}

Two measures were taken. First, the faculty instructor and graduate student instructors agreed to consistently and continuously emphasize and demonstrate to students the importance of algorithmic thinking and programming to the identity of engineers and to their work. Second, the weekly assignments were to be, as much as possible, placed in the context of technology applied to the improvement of society, to current events, or to technologies with which the students were very familiar.

The importance of computing and of the class to engineers and their education was emphasized during the first week of class, as it always had been. But, as part of the intervention, this context setting was carried forward throughout the term. Specifically, all graduate student instructors were asked to emphasize and repeat this importance throughout the term. Further, roughly once a week, 5 to 10 minutes of lecture time was spent showing the use of algorithms and computing in 
engineering or the place of programming within the College of Engineering curriculum. To counter the impression that the class is really just important for students headed to computer science or engineering, many courses across all of the undergraduate engineering majors were reviewed to show where those courses assumed an ability to program. Mention was made of professional engineering analysis, domain specific programming languages, and computational engineering websites, and care was taken to show how these were dominated by engineering practice in fields other than computer science or computer engineering.

Furthermore, the 2003 CACHE survey of practicing chemical engineers was reviewed (http://www.che.utexas.edu/cache/survey/) to show the importance placed on the subject by practicing engineers. One perception reinforced in this survey is the positive correlation between problem-solving skills and computer skills. This is a message on which Engin 101 is in part founded: learning to think logically and carefully as required to successfully implement an algorithm will reward the student in solving problems even when a computer code is not created. The few minutes spent on these presentations sometimes provided a good way to break the lecture into 20-minute chunks, and thereby prevent students from glazing over halfway through the class meeting.

A second part of the intervention involved placing the assignments in contexts intended to bolster student achievement by increasing the intrinsic and utility value of the tasks. There were two kinds of assignment given: 1) regular assignments, which could be completed in consultation with other students; and 2) practical assignments, which had to be attempted individually with no help from others (except possibly course instructors). The actual algorithms required by the regular assignments were quite similar to those given in previous terms. However, in the Fall 2004 term, there was consistent and extensive effort to put the assignments into a context related to engineers' contributions to society. Each Friday a significant amount of lecture time (occasionally most of it) was given to introducing the assignment, the ideas behind it, and its real world context.

The practical assignments were intended to address two problems with student work in the class that the researchers believed affected their ability to do well on in-class exams: 1) that they relied too much on autotesters and similar feedback tools provided by the instructors, and as a result did not sufficiently develop testing and troubleshooting skills; 2) they relied too much on group work and lacked individual accountability for learning the course material.

The assignments for Fall 2004 were:

1) Genesis: The task was to compute the terminal velocity of the Genesis space probe, which fell to Earth shortly before the assignment was given. This was really a simple formula evaluation exercise placed into a current technological event.

2) Tactical High Energy Laser: targeting a laser against a mortar round with a high-energy laser system. A system of this kind had been tested a few weeks before. The purpose of this kind of system is to protect troops from mortar attacks, and at the time U.S. troops in Iraq were all too often under mortar attack.

3) Transcendental functions: Students created algorithms to compute trigonometric functions using basic operations $\left(+,-,{ }^{*}, /\right)$ and iteration. The assignment emphasized the 
importance of these functions to the study of structural vibrations, the behavior of electrons in electronic devices, and their relation to the exponential function and even to population dynamics.

4) First practical: In this assignment the students were given three codes and required to test and correct them. One converted Fahrenheit to Celsius, one fit a parabola through three points in the plane, and one determined a best-fit line through many points. These tasks were closely related to previous assignments.

5) Gamma Knife: The task was to model the transport of gamma rays through matter using the Monte Carlo method, and this task was motivated within the context of the Gamma Knife, a technique used to treat deep-seated brain tumors. Students were reminded of the large numbers of Americans that are diagnosed with cancer every year, and the large numbers treated with radiation. The class was asked to raise their hands if they knew anyone who had had cancer - in any class of 225 a sea of hands will appear.

6) Colorize: When the Google search engine is used to search the Web, it will provide cached copies of web pages in which the search terms are marked in color. The assignment was to recreate this functionality by creating and implementing an algorithm that will read an html file and create a new version of the page in which a number of specified words have been colored using html tags. Students are of course very familiar with Google, and this context was felt to give meaning to what is otherwise a basic searching and text manipulation assignment.

7) Second practical: The students were once again given a defective code to repair, this one to find the largest and smallest number from a long list stored in a file. In a second part of the assignment, students were required to complete a code to find the median of a long list of numbers stored in a file.

8) Sharpen an image: The Mars Global Surveyor measurements of gamma rays and neutrons had recently provided a map of subsurface water on Mars. This assignment was to use the $1 / \mathrm{r}^{2}$ fall-off in intensity with distance to sharpen such an image. The assignment is really to solve a very large system of linear equations using the algebraic reconstruction technique, but can be placed in the context of improving an existing state-of-the-art measurement. Visualization of data with MATLAB was used.

9) Contaminant: The task was to create a model of the diffusion of a subsurface pollutant. This was placed within the context of an existing 1,4-dioxane plume from an industrial plant near the University of Michigan's Ann Arbor campus. The model was then used to demonstrate that the removal of the pollutant by an extraction well would be very much slower than its injection. The entire simulation was written in MATLAB, and visualization of the data with MATLAB was also used.

10) Minesweeper: Students were given an incomplete implementation of Minesweeper in MATLAB and required to finish it. This was neither topical nor technological, but it was fun to play.

\section{Method of Evaluation}

To evaluate the instructional intervention, researchers from the School of Education administered initial (week 2) and follow-up (week 13) online surveys to students $(n=447)$ enrolled in two different sections Engin 101 during Fall semester of 2004. The treatment group $(n=221)$ experienced the instructional intervention, and the remaining students $(n=226)$, taught by an 
instructor who did not use the intervention, provided a similar student population for comparison to the treated section. We will subsequently refer to this parallel group as a "control group."

The absence of a true control group is a limitation of this evaluation study. Most importantly, it was impossible to control for the nature of the weekly assignments in the control group.

Conversations with the instructor for the control group revealed that he also attempted to develop contexts for the programming assignments that would engage and interest students. For example, his assignments included mixing two audio files using Fast Fourier Transforms, GPS systems, modeling HIV responses to Protease Inhibitor Therapy, and decoding messages using a genetic algorithm. This limited our ability to determine whether the context of the assignments increased student interest in the assignments or, in the parlance of motivation theory, the intrinsic value of the task. To deal with this confounding factor, we focused our analysis on the effect of the intervention on two dimensions of student motivation that have been shown to affect persistence and achievement: importance (attainment value) and usefulness (utility value). Furthermore, in our regression analysis, we controlled for whether the students found the weekly assignments interesting.

The intervention involved not only changing the nature of the class assignments but also directly addressing with students the importance of programming and algorithmic thinking to their future as engineering majors and as practicing engineers. On this aspect of the intervention we believe we have more of a true control group. More specifically, the instructor for the control group told us directly that, although he did mention the importance of algorithmic thinking at the beginning of the term, he did not apply the steps outlined in the first part of the intervention - that is, to consistently have instructors and graduate student instructors reinforce to students the importance of programming during class and to intentionally devote weekly class time to showing examples of the value of the class content in their later classes and their future careers. We will therefore refer to the untreated group as a control group, although the difficulties of establishing a true control in comparing two course sections must be recognized.

Chi-square tests of independence revealed no statistically significant difference at the .01 level between the treatment or control groups on background characteristics such as gender, race, academic rank, current mathematics course, use of e-mail or the internet, commitment to engineering, and self-reported academic ability. Survey respondents were representative of the gender and racial composition of the class as a whole. The response rate for the treatment group was 57 percent for the initial survey and 53 percent for the follow-up survey; the response rate for the control group was 61 percent for the initial survey and 50 percent on the follow-up survey. For the treatment group 96 out of 221 students participated in both surveys, and for the control group 98 out of 226 participated in both surveys; coincidently, this is 43 percent of both the treatment (96/221) and control (98/226) group.

To measure student perceptions of importance and usefulness, respectively, we asked students to rate the extent to which they agreed with the statements: (1) It is important that engineering majors learn to program, and (2) I can see/imagine how the ideas from this class will be applied in my future career. Both questions used a 4-point Likert scale $(1=$ strongly disagree, $2=$ disagree somewhat, $3=$ agree somewhat, $4=$ strongly agree). We intentionally chose to omit a "neutral" category because the student interviews discussed in the introduction section had 
already revealed that students tended not to be neutral but in fact tended towards agreeing or disagreeing about various aspects of the course. Further, we wanted to force the students to think about the question and make a conscious choice. Thus, we believed that using a forced-response Likert scale would more usefully capture student perceptions of the importance and utility of the course.

For ease of reading and to focus the reader's attention to usefulness as a motivational variable, we will substitute the word "useful" for "applied" when referring to the second question. Also, in the interest of space, we will often refer to these questions as measuring the extent to which students found the course important or useful, respectively.

We conducted several types of analyses. First, we ran descriptive statistics of the variables used in this analysis. Next, in preparation for running t-tests to compare group means, we examined the frequency distribution for the survey questions related to perceptions of importance and usefulness, and we conducted a Jarque-Bera test for normality. This analysis revealed that the ttest assumption of normality was violated, and that these variables tended to be negatively skewed. However, for sample sizes greater than 40 , the t-test is robust to departures of normality and can be used for even for skewed distributions ${ }^{5}$.

We compared the treatment and control group's mean responses to these questions, and we also compared the mean difference in their response from the initial to the final survey by subtracting the agreement ( 1 through 4 ) of each student on the initial survey from their agreement on the final survey. We conducted a $t$-test to determine if the mean difference was statistically significantly different from zero.

Second, in order to control for the effects of variables such as gender, race, prior programming experience, and group membership (treatment or control) in predicting agreement that it is important that engineering majors learn to program and that the ideas from the course will be useful in their future careers, we ran two ordinary least squares (OLS) regressions using data collected on the follow-up survey. Independent variables were chosen so that the model was as parsimonious as possible due to the small sample size $(n=222)$. Gender and race were included in the model, as they were of interest to the researchers. We also included variables such as prior programming experience, liking to use computers, and the extent to which students believed they were proficient in $\mathrm{C}++$ because our interview data suggested that students rating themselves high on these categories were better able to focus on the algorithmic thinking in the course and, as a result, tended to view the course as important and useful because they were not overwhelmed by the syntax requirements of programming.

Several variables were excluded due to problems with multicolinearity. For example, whether students found the problems on the assignments interesting was highly collinear with liking the class $(r=.51, p=.00)$. Thus, we omitted the latter variable because of our interest in exploring the effects of interest in the weekly programming assignments and because interest or intrinsic value is a recognized motivational variable. Table 1 shows the variables used in the regressions, and Table 2 shows descriptive statistics for these variables. 
Table 1

Response variables used in the regression

Variable Name Variable Description

Dependent Variables

It is important that engineering majors learn to program

I can see/imagine how the ideas from this class will be applied in my future career

1 - strongly disagree...4 - strongly agree* $^{*}$

1 - strongly disagree...4 - strongly agree $^{*}$

\section{Independent Variables}

Female

1 if yes, 0 otherwise

Under represented minority

1 if yes, 0 otherwise

Had prior programming experience

1 if yes, 0 otherwise

I like to use computers

1 - strongly disagree...4 - strongly agree $^{*}$

I am proficient in programming in $\mathrm{C}++$

How committed are you to being an engineering major?

1 - strongly disagree...4 - strongly agree $^{*}$

1 - strongly disagree...4 - strongly agree $^{*}$

The problems solved in the programming assignments were interesting to me.

1 - strongly disagree...4 - strongly agree $^{*}$

Treatment Group

1 if yes, 0 otherwise

*1 - strongly disagree, 2 - disagree somewhat, 3 - agree somewhat, 4 - strongly agree

After running the regressions, we explored the model fit by adding variables at each step of the regression and comparing the restricted to the unrestricted model at each step. Care was taken to ensure that the restricted and unrestricted models used the same sample. Regression diagnostics revealed three cases in each regression that were either outliers with large influence or cases that had large leverage and large influence. Upon examination, each case appeared to be valid and not due to data collection errors. We reran the two regressions with these cases omitted, and there were no major changes in the measures of model fit and only slight changes in the regression coefficients. Finding no reasonable rationale for omitting these cases, they were included in the regression.

Finally, we conducted a supplement analysis of class grades during Fall of 2004 to explore any changes in the historical gap in course GPA by gender and race/ethnicity. Confidentiality issues associated with student grades limited us to exploring class grades in the aggregate. We acknowledge the limitations of drawing conclusions based on historical data. However, we present our results because of the College of Engineering's interest in closing existing grade gaps in the course. 
Table 2

Descriptive statistics of variables used in the regressions ${ }^{*}$

\begin{tabular}{|c|c|c|c|c|c|c|}
\hline Variable name & $N$ & $\%$ & Mean & S.D. ${ }^{\mathrm{a}} \mathrm{N}$ & Min. & Max. \\
\hline $\begin{array}{l}\text { It is important that engineering majors learn } \\
\text { to program }\end{array}$ & 230 & & 3.10 & 0.81 & 1 & 4 \\
\hline $\begin{array}{l}\text { I can see/imagine how the ideas from this } \\
\text { class will be applied in my future career }\end{array}$ & 230 & & 2.89 & 0.85 & 1 & 4 \\
\hline Female & 67 & 29.26 & & & & \\
\hline Under represented minority & 14 & 6.28 & & & & \\
\hline Had prior programming experience & 78 & 33.91 & & & & \\
\hline I like to use computers & 230 & & 3.46 & 0.68 & 1 & 4 \\
\hline I am proficient in programming in $\mathrm{C}++$ & 230 & & 2.99 & 0.78 & 1 & 4 \\
\hline $\begin{array}{l}\text { How committed are you to being an } \\
\text { engineering major? }\end{array}$ & 230 & & 3.30 & 0.78 & 1 & 4 \\
\hline $\begin{array}{l}\text { The problems solved in the programming } \\
\text { assignments were interesting to me. }\end{array}$ & 230 & & 2.91 & 0.86 & 1 & 4 \\
\hline Treatment Group & 118 & 51.30 & & & & \\
\hline
\end{tabular}

${ }^{*}$ Sample included all students who completed the follow-up survey $(n=230)$

${ }^{\mathrm{a}}$ Standard deviation of sample

The histogram of residuals appeared approximately normal for both regressions. The Q-Q plots suggested no severe departure from normality. The scatter plot of standardized residual by standardized predicted showed mild heteroscedasticity in that negative standardized predicted values had associated positive standardized residuals and positive standardized predicted values had associated negative standardized residuals.

\section{Results}

Table 3 shows the extent to which treatment and control group agreed on the initial and followup surveys that it is important that engineering majors learn to program and that the ideas from the course will be useful in their future careers. The final two lines of Table 3 show the mean difference in response to these questions between the two surveys.

Table 3 shows that on the initial survey, t-tests revealed no statistically significant difference between the treatment and the control group in their agreement about the importance $(p=.49)$ and usefulness ( $p=.12)$ of the course. On the follow-up survey, the treatment group $(m=3.26)$ was significantly more likely than the control group $(m=2.92)$ to believe that it is important that engineering majors learn to program $(t=10.77, p=.00)$. The effect size was medium (Cohen's $d=.43, r=.21$ ). There was no statistically significant difference between the two groups in agreeing that the ideas from the course will be useful in their future careers $(p=.33)$. 
Table 3

Mean responses (std. dev.) on initial and follow-up survey questions and mean difference in survey responses between initial and follow-up surveys

It is important that engineering majors learn to program
I can see/imagine how the ideas from this class will be applied in my future career

Initial Survey

Treatment Group $(n=138)$

$3.12(.70)$

Control Group $(n=127)$

3.32(.72)

$3.06(.72)$

Follow-up Survey

Treatment Group ( $n=118)$

$3.26(.72)^{* *}$

2.94(.83)

Control Group $(n=112)$

$2.92(.86)^{* *}$

$2.83(.87)$

\section{Mean Difference}

Treatment Group $(n=96)$

$-.18(.68)^{*}$

$-.17(.86)^{\sim}$

Control Group $(n=98)$

$-.42(.83)^{* *}$

$-.19(.92)^{*}$

${ }^{\mathrm{a}} 1$ - strongly disagree, 2 - disagree somewhat, 3 - agree somewhat, 4 - strongly agree

${ }^{\mathrm{b}}$ Computed by subtracting initial response from follow-up response. T-test used to determine whether the mean difference is statistically significantly different from 0 .

$\sim \mathrm{p}<.10,{ }^{*} \mathrm{p}<.05,{ }^{* *} \mathrm{p}<.01 . T$ test used to compare treatment and control group means.

The final two lines of Table 3 reveal that both the treatment and control group experienced a statistically significant mean decrease in agreement that the course is important and useful between the initial and follow-up survey. However, the decreases were more marked for the control group, suggesting the possible positive benefits of the intervention. Specifically, the mean difference of -.18 for the treatment group in agreeing that it is important that engineering majors learn to program was statistically significant at the .05 level $(p=.012)$, while the mean difference of -.42 for the control group on this question was statistically significant at the higher .01 level $(p=.000)$. A further post-hoc analysis revealed that the mean differences of -.18 and -.42 for the treatment and control groups, respectively, were themselves significantly different $(t=4.79, p=.03)$. The effect size was small to medium (Cohen's $d=.32, r=.16)$.

Furthermore, on the question of usefulness, the mean difference of -.17 for the treatment group was significant at the .10 level $(p=.06)$ while the mean difference of -.19 for the control group was significant at the higher .05 level $(p=.04)$. A post-hoc examination of a contingency table revealed that between the initial and follow-up surveys, the percentage of respondents who agreed strongly or somewhat that it is important that engineering majors learn to program 
dropped from 94 percent to 86 percent for the treatment group and 91 percent to 70 percent for the control group. The percentage of respondents who agreed strongly or somewhat that they could see how the ideas from the course will be useful in their future careers dropped from 88 percent down to 78 percent for the treatment group and from 86 percent to 68 percent for the control group.

As mentioned in the methods section, it was impossible to control for the nature of the weekly programming assignments given to the control group, which limited our ability to explore the effect of problem context on student interest in the assignments. An analysis of survey questions related to the weekly assignments revealed no significant difference between the treatment and control groups in (1) whether they found the problems on the assignments interesting, (2) whether the topics helped motivate them to work on the assignments, or (3) whether the assignments helped them understand how programming is used in engineering. The mean on all of these questions was close to 3 on a Likert scale of 1 to $4(1=$ strongly disagree . . . $4=$ strongly agree)

Table 4 shows the correlation coefficients for the variables in the two OLS models.

Table 4

Correlation coefficients for variables in the two OLS models

\begin{tabular}{|c|c|c|}
\hline & $\begin{array}{l}\text { It is important that } \\
\text { engineering majors } \\
\text { learn to program }\end{array}$ & $\begin{array}{l}\text { I can see/imagine how the } \\
\text { ideas from this class will } \\
\text { be applied in my future } \\
\text { career }\end{array}$ \\
\hline Female & -0.03 & -0.04 \\
\hline Under represented minority & -0.03 & 0.04 \\
\hline Had prior programming experience & $0.12 *$ & $0.17^{* *}$ \\
\hline I like to use computers & $0.27 * *$ & $0.26^{* *}$ \\
\hline I am proficient in programming in $\mathrm{C}++$ & $0.39 * *$ & $0.42 * *$ \\
\hline $\begin{array}{l}\text { Commitment to being an engineering } \\
\text { major }\end{array}$ & $0.25^{* *}$ & $0.30 * *$ \\
\hline $\begin{array}{l}\text { The problems solved in the } \\
\text { programming assignments were } \\
\text { interesting to me. }\end{array}$ & $0.32 * *$ & $0.46^{* *}$ \\
\hline Treatment Group & $0.20 * *$ & 0.05 \\
\hline
\end{tabular}

${ }^{*} \mathrm{p}<0.5,{ }^{* *} \mathrm{p}<.01$

The correlation table along with scatter plots of these variables revealed that, for both models, there was a linear relationship between the dependent variables and all the independent variables 
except gender and race and, in the case of believing that the ideas from the course were useful to their future careers, membership in the treatment group. We left these variables in the model because of their theoretical interest. Table 5 shows the regression coefficients $(B)$, standard errors $(S E)$, and standardized regression coefficients $(\beta s)$ for the two OLS models. Table 6 shows the adjusted- $R^{2}$ that resulted from adding variables to the model and comparing the restricted to the unrestricted model at each step.

Table 5

OLS regression results for the two models

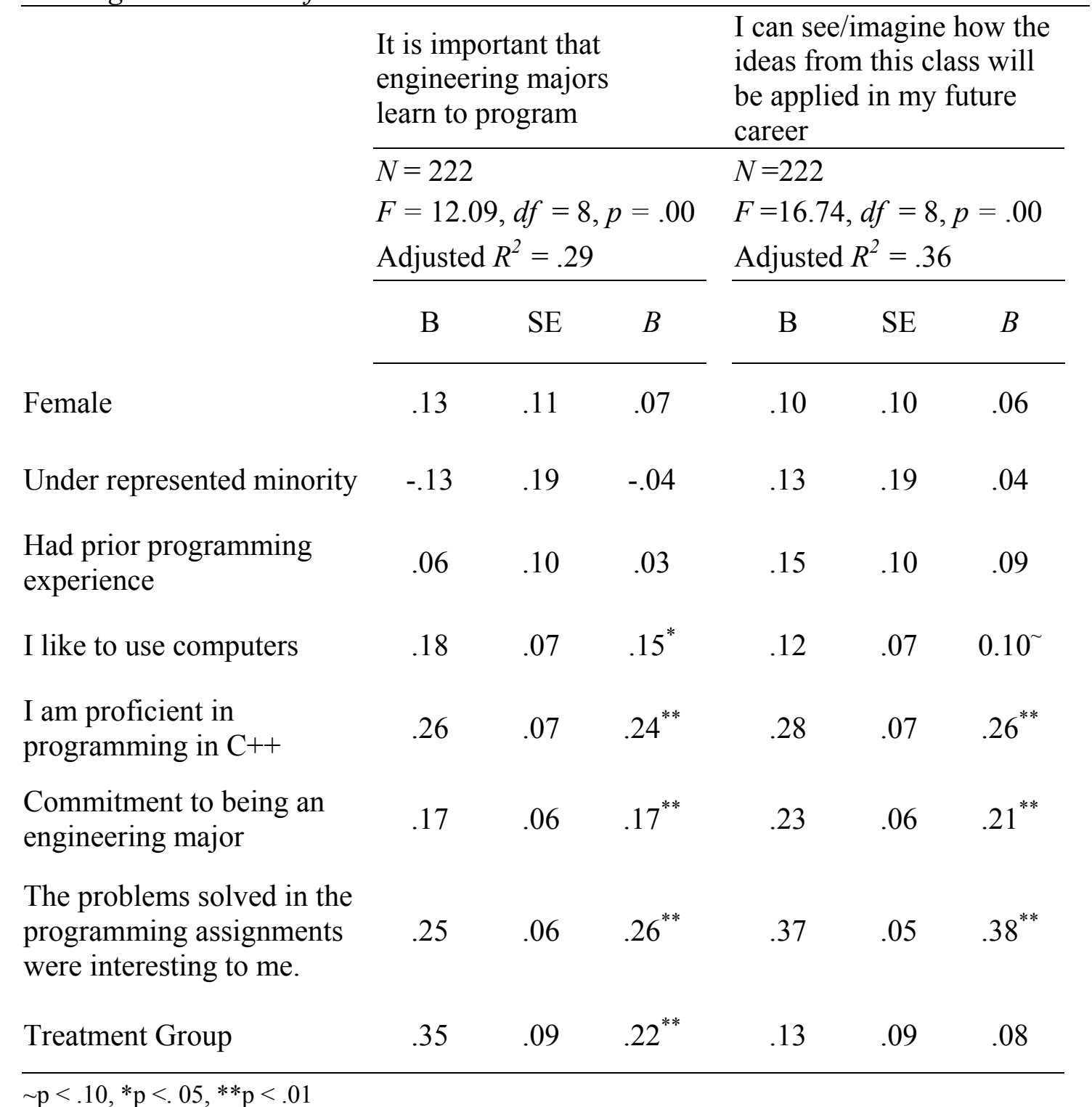

$\sim \mathrm{p}<.10,{ }^{*} \mathrm{p}<.05, * * \mathrm{p}<.01$ 
Table 6

Adjusted $R^{2}$ statistics for nested

OLS models

It is important that engineering majors learn to program
I can see/imagine how the ideas from this class will be applied in my future career

Model 1: Gender, race/ethnicity, prior programming experience

Model 2: Add liking to use computers"

Model 3: Add proficiency in programming in $\mathrm{C}++$

Model 4: Add engineering commitment

Model 5: Add interest in weekly programming assignments

Model 6: Add treatment group membership

The overall model predicting students' agreement that it is important that engineering majors learn to program was significant $(F=12.09, d f=8$, Signif $F=.00)$. Adjusted $R^{2}$ indicates that the independent variables together explained 29 percent the variance in the dependent variable, which is respectable though not stellar for social science research. A student's belief that the problems solved in the programming assignments were interesting was the most significant predictor of their agreement that it is important that engineering majors learn to program ( $\beta=.26, t=4.47, p=.00$ ). Table 6 reveals that this variable accounted for 5 percent of the explained variance. A student's belief that they were proficient in programming in $\mathrm{C}++$ was also a significant predictor $(\beta=.24, t=3.82, p=.00)$ in the model. This variable accounted for the largest percentage of the explained variance (11 percent) relative to other variables in the model.

Being in the treatment group was a significant predictor $(\beta=.22, t=3.78, p=.00)$ of agreeing that it is important that engineering majors learn to program even when controlling for the other variables in the model and accounted for 5 percent of the explained variance. Other significant predictors included a student's commitment to being an engineering major ( $\beta=.17, t=2.89$, $p=.00)$ and liking to use computers $(\beta=.15, t=2.42, p=.02)$. These two variables accounted for 2 and 6 percent of the explained variance, respectively. Gender, race, and prior programming experience were not significant predictors of agreeing that it is important that engineering majors learn to program. 
Next, the overall model predicting students' agreement that the ideas from the course will be useful in their future careers was significant $(F=16.74, \mathrm{df}=8$, Signif $F=.00)$. Adjusted $R^{2}$ indicated that the independent variables together explained 36 percent of the variance in the dependent variable. As with the prior model, the most significant predictor of agreeing that the ideas from the course will be useful in their future careers was believing that the problems solved in the programming assignments were interesting $(\beta=.38, t=6.70, p=.00)$. Table 6 reveals that this variable accounted for 12 percent of the explained variance.

A student's belief that they are proficient in programming in $\mathrm{C}++$ was also a significant predictor ( $\beta=.26, t=4.26, p=.00$ ) in the model and accounted for 13 percent of the explained variance.

Other significant predictors were being committed to being an engineering major $(\beta=.21, t=3.78$, $p=.00)$ and liking to use computers ( $\beta=.10, t=1.70, p=.09$ ), although the latter was only significant at the lower .10 level. These two variables accounted for 4 and 5 percent, respectively, of the explained variance.

Treatment group membership was not a significant predictor of a student's agreement that the ideas from the course will be useful in their future careers. As with the previous model, gender, race, and prior programming experience were not significant predictors.

Finally, a supplemental analysis conducted using historical data (acknowledging the limitations of doing so) comparing class grades is illuminating. The grade gap between male and female students dropped from 0.42 in Fall 2004 to 0.17 in Fall 2005, while the gap between majority and minority students dropped from 0.68 to 0.56 . This improved performance could be traced to narrowing the gap in both exam and homework scores. For female students, exam performance dominated. Specifically, the 8-percentage-point gap in exam scores by gender narrowed to 3 percentage points between Fall of 2003 and Fall of 2004. For under represented minority students, homework performance dominated. In this time period, the 6-percentage-point gap in homework scores between under represented minority students and majority students decreased to 2 percentage points.

\section{Discussion}

This study sought to explore the effects of an instructional intervention aimed at bolstering achievement by increasing student motivation in a required, first-year course in computers and programming in the College of Engineering at the University of Michigan. Using a theoretical framework for student motivation developed by Wigfield and Eccles ${ }^{10}$, the intervention sought to increase students' perception of the attainment value (importance) and utility value (usefulness) of the course. The intervention involved the lead instructor and graduate student instructors consistently and continuously emphasizing and demonstrating to students the importance of algorithmic thinking and programming to the identity of engineers and to their work. In addition, the weekly assignments were, as much as possible, placed in the context of technology applied to the improvement of society, to current events, or to technologies with which the students were very familiar.

To evaluate the instructional intervention, we administered initial and follow-up surveys to students $(n=447)$ enrolled in two different sections of Engin 101 during Fall semester of 2004. 
The treatment group $(n=221)$ experienced the instructional intervention, and the remaining students $(n=226)$, taught by an instructor who did not formally use the intervention, acted as a quasi-control group. In both the treatment and control groups, 43 percent of the students participated in both surveys.

As discussed in the methods section, our study is limited by the lack of a true control group. In particular, the control group instructor made efforts to place his weekly assignments into engaging and socially relevant contexts. However, the control group instructor agreed that he did not consistently and continuously discuss with students the importance of programming to their futures as engineering majors.

The remainder of this discussion section focuses on specific findings with respect to the effect of the intervention as revealed by the regression analysis and by an historical comparison of grades, acknowledging the limitations of the latter. We conclude by discussing several implications that derive from examining specific predictors in the models: (1) interest in the weekly assignments, (2) student demographics, and (3) proficiency in programming.

The results of the evaluation suggest that the intervention had a positive effect on increasing students' perception about the importance of the course. Specifically, on the follow-up survey, students in the treatment group were more likely to agree that it is important that engineering majors learn to program even when controlling for demographic variables, prior programming experience, liking to use computers, proficiency in programming, commitment to engineering, and interest in the programming assignments. The strength of this finding, which suggests that faculty behavior can have a direct influence on student motivation, is bolstered by our belief that we had a true control group for this aspect of the intervention.

The effect of the intervention on students' perceptions of the usefulness of the course is less clear. More specifically, in the regression analysis, treatment group membership was not a significant predictor of a student's agreeing that they can see or imagine how the ideas from the course would be applied in their future careers. We believe this results is attributable to the fact that a student's perceptions about the usefulness of a course is influenced most strongly by the tasks instructors ask them to engage in. In Engin 101, the weekly assignments comprise the tasks. Yet we were unable to control for the nature of the programming assignments in the control group. Between the initial and follow-up surveys, $t$ tests revealed that both groups had a very negligible negative decrease in mean response to questions about the usefulness of the course. Further, the slight difference in the mean decrease, although it favors the treatment group, has little practical significance. That said, we would note that these results are a marked improvement from survey results from a year prior, where students had an overall mean decrease of -.5 in response to this question between the initial and follow-up surveys. Again, we acknowledge the limitations of making historical comparisons.

We focused our intervention on increasing students' perceptions about the importance and usefulness of the course because these aspects of motivation have been shown to be positively associated with higher levels of achievement. Yet our evaluation was limited by our inability to link survey results with individual student grades. Our analysis of course grades in the aggregate revealed that the gap between males and females and between minority and majority students 
narrowed during the semester of the intervention compared with a year earlier. However, we remind the reader of the limitations of drawing conclusions based on historical data, and we are not claiming that the intervention had an effect on this narrowing.

An additional important finding of this study is the strength of student interest in the weekly assignments as a predictor of finding the course important and useful. We know from personal experience that it takes considerable extra effort on the part of faculty to create course assignments that truly interest and engage students. However, this study provides evidence of the pay-off faculty can derive vis-à-vis increased student motivation. More specifically, a student's interest in the weekly programming assignments was the strongest predictor of that student's agreeing that it is important that engineering majors learn to program as well as agreeing that the course would be useful in their future careers.

Also compelling is the finding that gender, under-represented minority status, and prior programming experience - factors that might be assumed to influence student motivation in an introductory programming course - were not significant predictors in either model. These findings help to defy any stereotypes we might hold that student motivation in this course is largely an intrinsic factor that is dictated by the entering characteristics of students.

Finally, we wish to highlight that, in both models, a student's self-reported proficiency in programming in $\mathrm{C}++$ was the second strongest predictor of perceived importance and usefulness after interest in the weekly assignments. In fact, this variable accounted for the majority of the explained variance in both models. In the model predicting agreement that it is important that engineering majors learn to program, self-reported proficiency in programming $(\beta=.24)$ had nearly the same predictive strength as a student's interest in the weekly assignments $(\beta=.26)$ and treatment group membership $(\beta=.22)$.

This correlation between programming proficiency and perceptions of importance and usefulness is encouraging given the results from the qualitative study discussed in the introduction section. In that study, students who self-reported being proficient in programming seemed better able to focus on the algorithmic thinking in the course because they were not overwhelmed by the syntax requirements of programming. Yet 75 percent $(15 / 20)$ of interview participants in that study, including students who considered themselves to be proficient in programming, did not consider programming and algorithmic thinking to be key features of their identities as engineers, and they did not understand how programming would be utilized in their chosen majors. It appears, then, that the intervention helped these students see the importance and usefulness of Engin 101.

However, this finding should also serve as a warning that future interventions to bolster student motivation should include measures aimed specifically at improving programming proficiency. Otherwise, our model predicts that lower levels of proficiency might cancel out the positive effect of creating interesting contexts for the weekly assignments as well as the positive benefits of directly addressing with students the importance of programming to engineering majors. 


\section{Bibliography}

1. Bloom, B.S. (1954). Taxonomy of educational objectives: Handbook 1: Cognitive domain. New York: McKay.

2. Eccles, J. (1994). Understanding women's educational and occupational choices. Psychology of Women Quarterly, 18, 585-609.

3. Linn, M.D., \& Hyde, J.S. (1989). Gender, mathematics, and science. Educational Researcher, 18(8), $17-27$.

4. McKeachie, W.J. (1999). Teaching tips: Strategies, research, and theory for college and university teachers. Boston: Houghton Mifflin Company.

5. Moore, D.S., \& McCabe, G.P. (1999). Introduction to the practice of statistics. New York: W.H. Freeman and Company.

6. Pintrich P. \& Zusho, A. (2002). Student motivation and self-regulated learning in the college classroom. In J.C. Smart \& W.G. Tierney (Eds.), Higher education: Handbook of theory and research. Boston: Kluwer Academic Publishers.

7. Seymour, E. \& Hewitt, N.M. (1997). Talking about leaving: Why undergraduates leave the sciences. Boulder, CO: Westview Press.

8. Tinto, V. (1993). Leaving college: Rethinking the causes and cures of student attrition. Chicago: University of Chicago Press.

9. Tobias, S. (1990). They're not dumb, they're different: Stalking the second tier. Tucson, AZ: Research Corporation.

10. Wigfield, A., \& Eccles, J. S. (2000). Expectancy - value theory of motivation. Contemporary Educational Psychology, 25, 68-81. 